ISSN 0103-9954

\title{
ESTRUTURA DO COMPONENTE ARBÓREO E ARBORESCENTE DE UM FRAGMENTO URBANO NO MUNICÍPIO DE SÉRIO, RIO GRANDE DO SUL, BRASIL
}

\author{
TREE AND ARBORESCENT COMPOSITION IN A URBAN FOREST FRAGMENT IN THE \\ MUNICIPALITY OF SÉRIO, RIO GRANDE DO SUL STATE, BRAZIL
}

\author{
Ana Paula Ariotti ${ }^{1}$ Fabiano Eduardo Eichler ${ }^{2}$ Elisete Maria de Freitas ${ }^{3}$
}

\begin{abstract}
RESUMO
Fragmentos urbanos rodeados por uma matriz habitacional constituem uma porção de floresta que preserva a riqueza e serve para conservação das relações dos seres vivos entre si e com o ambiente. O presente estudo teve por objetivo descrever a comunidade arbórea e arborescente do fragmento florestal urbano no município de Sério, Rio Grande do Sul (RS), inserido no Bioma Mata Atlântica, na formação fitoecológica da Floresta Estacional Decidual Montana. O levantamento florístico foi realizado através do método de caminhamento, atingindo toda a área, em saídas mensais. Para a amostragem, foram distribuídas 40 unidades amostrais (UAs) de $100 \mathrm{~m}^{2}$, distantes 20 metros entre si. Dentro das UAs foram obtidos os dados de altura e circunferência a altura do peito (CAP) de todos os indivíduos com CAP igual ou superior a $15 \mathrm{~cm}$. Foram estimados os parâmetros de dominância, densidade e frequência, absolutas e relativas, e o índice de valor de importância (IVI). O levantamento florístico indicou a ocorrência de 59 espécies arbóreas e arborescentes pertencentes a 48 gêneros e 30 famílias. No levantamento quantitativo foram amostrados 535 indivíduos arbóreos pertencentes a 51 espécies distribuídas em 42 gêneros e 27 famílias. Dentre as espécies, três são exóticas e três encontram-se na lista das espécies ameaçadas de extinção do RS. A densidade absoluta foi estimada em 1.338 ind.ha ${ }^{-1}$. Actinostemon concolor apresentou os maiores valores de densidade (140 ind. $\mathrm{ha}^{-1}$ ), seguida por Alchornea triplinervia e Eugenia rostrifolia, ambas com 108 ind.ha $^{-1}$. As espécies com os maiores IVIs foram Alchornea triplinervia, Vernonanthura discolor, Actinostemon concolor, Eugenia rostrifolia e Araucaria angustifolia. A diversidade estimada pelo índice de Shannon (H') foi de 3,35 e a equabilidade de Pielou (J') de 0,85, apontando uma considerável diversidade de espécies. O fragmento constitui um importante refúgio de espécies da flora nativa regional e, para que continue a cumprir com sua função ecológica, é necessária a implantação de medidas que visem a sua preservação, tais como, a eliminação dos indivíduos de espécies exóticas.
\end{abstract}

Palavras-chave: composição florística; comunidade arbórea; levantamento fitossociológico; Bioma Mata Atlântica.

\begin{abstract}
Urban forest fragments surrounded by housing matrix are a source of richness and can function as a conservation site in the relation between the living beings and the environment. The present study have as aim to describe the community structure of tree and arborescent species in a urban forest fragment in the municipality of Sério, Rio Grande do Sul (RS) state, inserted in the Atlantic Forest biome, phytoecological formation Montane Deciduous Forest. The floristic inventory was produced through walking method, reaching the total fragment area, in monthly field incursions. For sampling, 40 sampling units (UA's) of $100 \mathrm{~m}^{2}$ were scattered, with distance of 20 meters in between them. Inside the UAs, it was obtained the

1 Licenciada em Ciências Biológicas, Centro Universitário UNIVATES, Professora Municipal, CEP 95918-000, Sério (RS), Brasil. paulaariotti@hotmail.com

2 Acadêmico do Curso de Engenharia Ambiental, Centro Universitário UNIVATES, CEP 95918-000, Sério (RS), Brasil. feichler@universo.univates.br

3 Bióloga, $\mathrm{Dr}^{\mathrm{a}}$, Professora do Programa de Pós-Graduação em Biotecnologia, Centro Universitário UNIVATES, Rua Avelino Tallini, 171, Bairro Universitário, CEP 95900-000, Lajeado (RS), Brasil. elicauf@univates.br
\end{abstract}

Recebido para publicação em 10/12/2013 e aceito em 29/09/2014

Ci. Fl., v. 26, n. 3, jul.-set., 2016 
height and circumference at the chest height (CAP) of all specimens which have CAP equal or higher than $15 \mathrm{~cm}$. It was estimated the parameters of dominancy, density, frequency, absolute and relative, and the importance value index (IVI). The floristic inventory found 59 trees and arborescent species belonging to 48 genera and 30 families. In the quantitative inventory, 535 tree specimens belonging to 42 genera and 27 families were sampled. Among the species, three are exotic and three are in the threatened species list of the state of Rio Grande do Sul. The absolute density was estimated in 1,338 individuals $/ \mathrm{ha}^{-1}$. Actinostemon concolor showed the denser values (140 ind.ha $\left.{ }^{-1}\right)$, followed by Alchornea triplinervia e Eugenia rostrifolia, both with 108 ind.ha $^{-1}$. The species with the great IVI's were Alchornea triplinervia, Vernonanthura discolor, Actinostemon concolor, Eugenia rostrifolia and Araucaria angustifolia. The estimated diversity found through the Shanon Index $\left(\mathrm{H}^{\prime}\right)$ was 3.35 , and the equability of Pielou (J') was 0.85 , denoting a consistent species diversity. The fragment can be seen as an important shelter for the regional wild fauna and flora. However, to still working in its ecological roles we concluded that conservation and protection measures are needed in this area, being the removal of exotic species the first step to be taken..

Keywords: floristic composition; tree community; phytosociological inventory, Atlantic Forest Biome.

\section{INTRODUÇÃO}

Dentre as causas para o declínio da biodiversidade global está a degradação e a fragmentação de habitat, constituindo-se na mais importante ameaça para as comunidades animais e vegetais (GUREVITCH; SCHEINER; FOX, 2009). A razão para tamanha ameaça está nos danos causados à estrutura das florestas, pois promove alterações na biota, através de efeitos de borda, acúmulo de lixo, bioinvasões, medidas de manejo inadequadas, entre outras que vão descaracterizando e diminuindo as coberturas florestais (MELO et al., 2011).

Florestas nativas que têm sua extensão reduzida e que resistiram ao desgaste causado pelo processo de urbanização, suportando as ameaças que implicam no equilíbrio ecológico da flora e fauna da região são remanescentes de um ecossistema e se denominam fragmentos florestais urbanos (TROIAN et al., 2011). De acordo com os mesmos autores, são rodeados por uma matriz habitacional e constituem uma porção de mata que preserva a riqueza e serve para conservação das relações dos seres vivos entre si e com o meio ambiente.

Essas áreas verdes servem como corredores ecológicos, que exercem a função de fluxo gênico de diversas espécies e disponibilidade de recursos alimentares, pois permite a ligação entre fragmentos florestais, criando condições para perpetuação das comunidades vegetais e animais além de minimizar os efeitos causados pela fragmentação (CULLEN Jr. et al., 2003).

Avegetação em centros urbanos desempenha funções importantes que vão além de proporcionar o embelezamento da cidade e beneficiar as condições de vida da população, visto que a sombra gerada pelas árvores ameniza a radiação solar influenciando na redução da temperatura e nas correntes de ventos, contribuindo na redução da poluição através do processo de fotossíntese. Ela também favorece o bem-estar psicológico, pois o contato com a natureza é reflexo de paz e tranquilidade (FEIBER, 2004).

Um fator considerável para a preservação dos mesmos é a utilização desses espaços ou seus arredores para áreas de lazer que atraem visitantes. Assim, cria-se uma ferramenta de divulgação dos benefícios que oferecem à população, gerando um espaço de potencial educativo, que desperta a importância da preservação da biodiversidade e o manejo adequado dessas áreas verdes (CIELOFILHO; SANTIN, 2002; MELO et al., 2011).

O objetivo do presente trabalho consiste em descrever a comunidade arbórea e arborescente de um fragmento florestal urbano no município de Sério - RS, além de revelar a riqueza nativa existente, visto que existe um número reduzido de pesquisas realizadas em fragmentos urbanos, bem como de trabalhos de divulgação da biodiversidade do município de localização do referido fragmento.

\section{MATERIAL E MÉTODOS}

O presente estudo foi realizado num fragmento de floresta nativa situado na zona urbana do município de Sério, na Encosta da Serra Geral, região central do RS, nas coordenadas $29^{\circ} 22^{\prime} 56.31^{\prime \prime} \mathrm{S}$ e $52^{\circ} 16^{\prime} 0134^{\prime}$ 'O, em altitude máxima de $634 \mathrm{~m}$ (Figura 1). Os lados sul, norte 
e oeste do fragmento são cercados por residências e o lado leste é cercado por floresta exótica. Internamente é recortado por uma trilha para caminhadas e por cercas demarcando limites de propriedades atuais. Apresenta conectividade com um fragmento maior de floresta nativa, localizado após o campo de futebol, embora esteja dividido por uma rua que faz ligação da zona rural ao centro da cidade.

O solo da região estudada é classificado, segundo Streck et al. (2008), como Neossolo Regolítico Eutrófico. E o clima, de acordo com Köppen é classificado em "Cf' ou temperado úmido, apresentando a variedade "Cfa" ou subtropical na maioria das regiões (PEEL; FINLAYSON; MCMAHON, 2007).

A vegetação está inserida no Bioma Mata Atlântica sendo classificada como Floresta Estacional Decidual Montana, devido a sua altitude ser maior que $400 \mathrm{~m}$ (LEITE, 2002). Porém, apresenta grande influência da Floresta Ombrófila Mista em razão da proximidade que apresenta com esta.

Atualmente, parte do fragmento estudado é de propriedade da prefeitura, tendo sido adquirido junto com uma área de terras em 1997 com o objetivo de criar uma área de lazer aos munícipes. No entanto, tal prática está sendo implantada sem a orientação de profissionais técnicos, gerando danos ao fragmento, principalmente no estrato inferior mais perto da borda que vem sendo retirada frequentemente com o objetivo de, segundo os administradores municipais, "limpar a área". No passado a área era de propriedade particular, sendo parte utilizada para o pastejo do gado. Com o abandono da atividade, a vegetação se regenerou, sendo classificada atualmente, segundo a Resolução CONAMA33/1994, como secundária em estágio avançado de regeneração (BRASIL, 1994). No restante do fragmento, a vegetação é primária, no entanto, verifica-se que houve exploração de madeira no passado.

Para o levantamento florístico, toda a área foi percorrida em saídas mensais iniciadas em dezembro de 2011, seguindo o método de "caminhamento" proposto por Filgueiras et al. (1994). Nas saídas foi realizada a coleta de material botânico das espécies arbóreas e arborescentes não identificados de imediato. O material foi desidratado e herborizado para posterior identificação em laboratório. Quando fértil, foram confeccionadas exsicatas e incorporadas ao acervo do Herbário HVAT do Museu de Ciências Naturais do Centro Universitário UNIVATES. A identificação das espécies arbóreas foi realizada seguindo as chaves dicotômicas de Sobral et al. (2013) e consulta a especialistas. Para a identificação das famílias botânicas foi seguida a Angiosperm Phylogeny Group III (2009) e os nomes científicos das espécies nativas foram confirmados na Lista de Espécies da Flora do Brasil (2013). Para as espécies exóticas foi seguida a nomenclatura do Missouri Botanical Garden (TROPICOS, 2013).

O levantamento fitossociológico foi realizado entre os meses de abril a julho de 2013 através da amostragem dos indivíduos arbóreos existentes em 40 unidades amostrais (UAs) de 10 X 10 m, distribuídas a cada 20 metros ao longo de transectos também distantes 20 metros entre si. Em cada UA foram obtidos os dados dendrométricos (altura e circunferência a altura do peito - CAP) de todos os indivíduos com CAP igual ou superior a $15 \mathrm{~cm}$. Para o caso dos indivíduos com fustes ramificados, mediu-se a circunferência de cada ramo desde que pelo menos um dos fustes apresentasse o CAP mínimo considerado no estudo. A altura de cada um dos indivíduos foi estimada a partir da observação visual. As árvores exóticas presentes dentro das unidades amostrais e os indivíduos de Alsophila setosa Kaulf com o CAP mínimo estabelecido também foram amostradas.

A partir desses dados, foram estimados, para cada uma das espécies, os parâmetros: dominância absoluta e relativa $\left(\mathrm{DoA}_{\mathrm{i}} \mathrm{e} \mathrm{DoR}_{\mathrm{i}}\right)$, frequência absoluta e relativa $\left(\mathrm{FA}_{\mathrm{i}}\right.$ e $\left.\mathrm{FR}_{\mathrm{i}}\right)$, densidade absoluta e relativa $\left(\mathrm{D}_{\mathrm{i}} \mathrm{e} \mathrm{DR}_{\mathrm{i}}\right)$, índice de valor de importância (IVI) e índices de diversidade (índice de Shannon - H' e equabilidade de Pielou - J) (MUELLERDOMBOIS; ELLENBERG, 1974). A riqueza (S) amostrada na área foi estimada pelo estimador de riqueza Bootstrap a partir de uma matriz de presença e ausência no programa EstimateS (COLWELL, 2006).

\section{RESULTADOS E DISCUSSÃO}

\section{Florística}

No fragmento estudado foi registrada a ocorrência de 59 espécies pertencentes a 48 gêneros e 30 famílias botânicas (Tabela 1). A riqueza florística é semelhante à verificada por Jarenkow e Waechter (2001) que encontraram 23 famílias, 46 gêneros e 55 espécies em um componente arbóreo de uma Floresta Estacional no município de Vale do Sol, Rio Grande do Sul. 


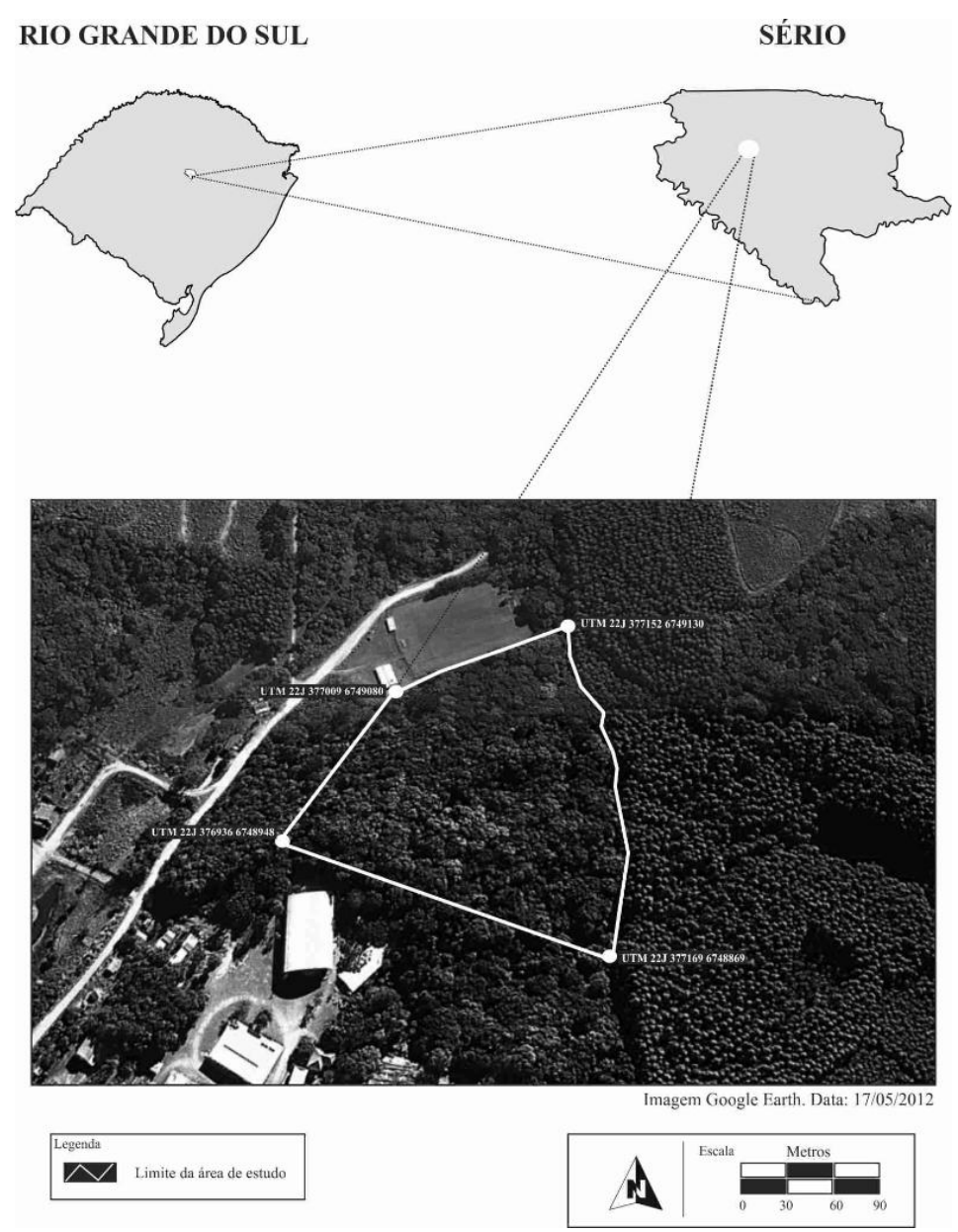

FIGURA 1: Localização e delimitação do fragmento florestal urbano estudado no município de Sério - RS, Brasil.

FIGURE 1: Location and area limits of the urban forest fragment studied in the municipality of Sério, RS state, Brazil.

As famílias com maior riqueza específica foram Myrtaceae com seis espécies, Euphorbiaceae e Lauraceae com quatro espécies. Sapindaceae, Rubiaceae, Primulaceae, Asteraceae, Solanaceae, Melastomataceae e Meliaceae foram representadas por três espécies. Quatro famílias foram representadas por duas espécies e as 16 restantes por apenas uma.

Myrtaceae, Euphorbiaceae e Lauraceae também foram destaque apresentando maior riqueza em um estudo realizado por Jurinitz e Jarenkow (2003) do componente arbóreo de uma Floresta Estacional na Serra do Sudeste, Rio Grande do Sul, Brasil. As três famílias também estiveram entre as mais numerosas no estudo de Jarenkow e Waechter (2001), realizado em uma floresta Estacional na região Central Sul-rio-grandense, e de Grings e Brack (2009) em uma mata nativa de Nova
Petrópolis. Além destes, Myrtaceae foi a família mais numerosa em uma análise fitossociológica de um fragmento de floresta Estacional Decidual no município de Jaguari - RS (HACK et al., 2005), em um levantamento fitossociológico arbóreo na região central da Planície Costeira do Rio Grande do Sul (DORNELES; WAECHTER, 2004), no estudo florístico de uma porção de mata de encosta do Morro da Harmonia, Teutônia - RS, Brasil (MARKUS; FREITAS, 2011) e em um fragmento de Mata Ciliar do arroio Boa Vista, Teutônia - RS, Brasil (BRAKMANN; FREITAS, 2013). Todos contribuem para a confirmação de que Myrtaceae é uma família que se evidencia em diferentes formações florestais do Estado.

Três espécies estão na lista de Espécies da Flora Ameaçada de Extinção do Rio Grande do Sul: Arancaria angustifolia, Ocotea silvestris 
TABELA 1: Lista das famílias e espécies encontradas em um fragmento florestal urbano no município de Sério - RS, Brasil, com os respectivos nomes populares e número de registro do herbário HVAT do Museu de Ciências Naturais do Centro Universitário UNIVATES.

TABLE 1: List of families and species found in the urban forest fragment in the municipality of Sério, RS state, Brazil. Showing the common names and the registration number of the species at the herbarium (HVAT) of the Natural Science Museum of UNIVATES.

\begin{tabular}{|c|c|c|}
\hline Família/Espécie & Nome popular & HVAT \\
\hline \multicolumn{3}{|l|}{ Anacardiaceae } \\
\hline Schinus terebinthifolius Raddi & Aroeira-vermelha & 342 \\
\hline \multicolumn{3}{|l|}{ Annonaceae } \\
\hline Annona neosalicifolia H.Rainer & Araticum & \\
\hline Annona rugulosa (Schltdl.) H.Rainer & Araticum & \\
\hline \multicolumn{3}{|l|}{ Aquifoliaceae } \\
\hline Ilex paraguariensis A.St.-Hil. & Erva-mate & 332 \\
\hline \multicolumn{3}{|l|}{ Araliaceae } \\
\hline Schefflera morototoni (Aubl.) Maguire et al. & Caixeta & \\
\hline \multicolumn{3}{|l|}{ Araucariaceae } \\
\hline Araucaria angustifolia (Bertol.) Kuntze & Pinheiro & \\
\hline \multicolumn{3}{|l|}{ Arecaceae } \\
\hline Bactris setosa Mart. & Tucum & \\
\hline \multicolumn{3}{|l|}{ Asteraceae } \\
\hline Gochnatia polymorpha (Less.) Cabrera & Cambará & \\
\hline Piptocarpha angustifolia Dusén ex Malme & Vassourão-branco & 347 \\
\hline Vernonanthura discolor (Spreng.) H.Rob. & Vassourão-branco & \\
\hline \multicolumn{3}{|l|}{ Cunoniaceae } \\
\hline Lamanonia ternata Vell. & Guaraperê & \\
\hline \multicolumn{3}{|l|}{ Cyatheaceae } \\
\hline Alsophila setosa Kaulf. & Samambaiaçu & \\
\hline \multicolumn{3}{|l|}{ Elaeocarpaceae } \\
\hline Sloanea hirsuta (Schott) Planch. ex Benth. & Carrapicheira & \\
\hline \multicolumn{3}{|l|}{ Euphorbiaceae } \\
\hline Actinostemon concolor (Spreng.) Müll.Arg. & Laranjeira-do-mato & 180 \\
\hline Alchornea triplinervia (Spreng.) Müll.Arg. & Tanheiro & \\
\hline \multicolumn{3}{|l|}{ Stillingia oppositifolia Baill. ex Müll.Arg } \\
\hline Pachystroma longifolium (Nees) I.M.Johnst. & Mata-olho & \\
\hline \multicolumn{3}{|l|}{ Lamiaceae } \\
\hline Vitex megapotamica (Spreng.) Moldenke & Tarumã & \\
\hline \multicolumn{3}{|l|}{ Lauraceae } \\
\hline Aiouea saligna Meisn. & Canela-vermelha & \\
\hline Endlicheria paniculata (Spreng.) J.F.Macbr. & Canela-sebo & \\
\hline Nectandra oppositifolia Nees & Canela-ferrugem & \\
\hline Ocotea silvestris Vattimo-Gil & Canela & \\
\hline Melastomataceae & & \\
\hline
\end{tabular}


TABELA 1: Continuação...

TABLE 1: Continued...

\begin{tabular}{llc}
\hline \multicolumn{1}{c}{ Família/Espécie } & \multicolumn{1}{c}{ Nome popular } & HVAT \\
\hline Leandra australis (Cham.) Cogn. & Pixirica & 345 \\
Miconia petropolitana Cogn. & Pixirica & 374 \\
Miconia pusilliflora (DC.) Naudin & Pixirica & 357 \\
Meliaceae & & \\
Cabralea canjerana (Vell.) Mart. & Cangerana \\
Guarea macrophylla Vahl & Pau-de-arco & \\
Trichilia clausseni C.DC & Catiguá-vermelho \\
Monimiaceae & & 329 \\
Hennecartia omphalandra J.Poiss. & Mata-olho-branco \\
Mollinedia schottiana (Spreng.) Perkins & Pimenteira \\
Moraceae & & \\
Sorocea bonplandii (Baill.) W.C.Burger et al. & Cincho \\
Myrtaceae & \\
Calyptranthes grandifolia O.Berg & Guamirim \\
Calyptranthes tricona D.Legrand & Guaburiti \\
Eugenia pyriformis Cambess. & Uvaia \\
Eugenia ramboi D.Legrand & Batinga-branca \\
Eugenia rostrifolia D.Legrand & Batinga-vermelha \\
Eugenia verticillata (Vell.) Angely & Batinga \\
Pinaceae & \\
Pinus elliottii Engelm. & Pinus \\
Piperacea & &
\end{tabular}

Piperaceae

Piper xylosteoides (Kunth) Steud.

Primulaceae

Myrsine laetevirens (Mez) Arechav.

Capororoca

360

Myrsine lorentziana (Mez) Arechav.

Capororoca

354

Myrsine umbellata Mart.

Capororoca

Proteaceae

Roupala montana var. brasiliensis (Klotzsch) K.S.Edwards

Carvalho

Rhamnaceae

Hovenia dulcis Thunb.

Uva-japonesa

Rosaceae

Eriobotrya japonica (Thunb.) Lindl.

Rubiaceae

Faramea montevidensis (Cham. \& Schltdl.) DC.

Café-do-mato

Psychotria suterella Müll.Arg.

Randia ferox (Cham. \& Schltdl.) DC.

Limoeiro-do-mato

Rutaceae

Esenbeckia grandiflora Mart.

Cutia

Zanthoxylum rhoifolium Lam.

Mamica-de-cadela 
TABELA 1: Continuação...

TABLE 1: Continued...

\begin{tabular}{ll}
\multicolumn{1}{c}{ Família/Espécie } & \multicolumn{1}{c}{ Nome popular } \\
\hline $\begin{array}{l}\text { Sabiaceae } \\
\text { Meliosma sellowii Urb. }\end{array}$ & Pau-fernandes \\
Salicaceae & \\
Casearia sylvestris Sw. & Chá-de-bugre \\
Xylosma pseudosalzmannii Sleumer & \\
Sapindaceae & \\
Allophylus edulis (A.St.-Hil. et al.) Hieron. ex Niederl. & Chal-chal \\
Cupania vernalis Cambess. & Camboatá-vermelho \\
Matayba elaeagnoides Radlk. & Camboatá-branco \\
Solanaceae & \\
Solanum mauritianum Scop. & Fumeiro \\
Solanum pseudoquina A.St.-Hil. & Tintureiro \\
Solanum sanctae-catharinae Dunal & Joá-manso \\
\hline
\end{tabular}

e Gochnatia polymorpha, todas na categoria vulnerável (SEMA, 2003). Três são consideradas exóticas: Eriobotrya japonica, Hovenia dulcis $e$ Pinus elliotti.

As espécies Hovenia dulcis e Eriobotrya japonica também foram encontradas no estudo realizado por Troian et al. (2011) em um fragmento florestal urbano de Floresta Estacional Decidual no município de Porto Alegre - RS. Da mesma forma que o encontrado no presente estudo, as espécies foram representadas por poucos indivíduos, porém, recomenda-se maior atenção quanto à dispersão destas espécies, visando impedir alterações que venham a comprometer a biodiversidade.

\section{Parâmetros Fitossociológicos}

No levantamento fitossociológico foram amostrados 535 indivíduos, distribuídos em 27 famílias botânicas, 42 gêneros e 51 espécies (Tabela 2). A estimativa de riqueza usada no presente trabalho estimou um total de 58 espécies para área, valor próximo à soma das espécies coletadas nas unidades amostrais (51), o que compreende certa estabilização a partir da UA 37, determinando que a amostra correspondeu a $88 \%$ da riqueza total estimada (Figura 2).

A densidade total estimada foi de 1.338 ind. $\mathrm{ha}^{-1}$, sendo a maior densidade de indivíduos obtida por Actinostemon concolor (140 ind.ha- ${ }^{-1}$ ), seguida por Alchornea triplinervia e Eugenia rostrifolia, ambas com 108 ind.ha $^{-1}$, Vernonanthura discolor (100 ind.ha-1) (Tabela 2). Actinostemon concolor e Alchornea triplinervia foram encontradas também por Markus e Freitas (2011) em uma porção de mata de encosta do Morro da Harmonia, no município de Teutônia - RS, cuja altitude e formação florestal são semelhantes ao fragmento do presente estudo.

Considerando o Índice de Valor de Importância (IVI) (Tabela 2), Alchornea triplinervia apresentou o maior valor $(13,87 \%)$, sendo seguida por Vernonanthura discolor (8,67\%), Actinostemon concolor (6,42\%), Eugenia rostrifolia (6,23\%) e Araucaria angustifolia (5,55\%). O valor elevado do IVI de Alchornea triplinervia está relacionada diretamente com a área basal que foi muito superior às demais espécies $\left(3,64 \mathrm{~m}^{2} \cdot \mathrm{ha}^{-1}\right)$. A posição de Actinostemon concolor é justificada pelo maior número de indivíduos (56) presentes no fragmento e não por sua área basal $\left(0,43 \mathrm{~m}^{2}\right.$. ha- $\left.\mathrm{a}^{-1}\right)$, sendo inferior à de Alchornea triplinervia.

Actinostemon concolor também atingiu valores elevados de IVI em um levantamento do componente arbóreo de uma Floresta Estacional na Serra do Sudeste - RS, Brasil, destacando-se no sub-bosque. No mesmo estudo também foi amostrada Alchornea triplinervia, porém, com valores inferiores em relação ao presente estudo, demonstrando reduzida densidade e dominância naquela comunidade vegetal (JURINITZ; JARENKOW, 2003).

Considerando o levantamento fitosso- 
TABELA 2: Parâmetros fitossociológicos estimados para as espécies arbóreas de um fragmento florestal urbano no município de Sério - RS, Brasil, em ordem decrescente de valor de importância (IVI) $(\mathrm{NI}=$ número de indivíduos, $\mathrm{AB}=$ área basal, $\mathrm{DA}=$ densidade absoluta, $\mathrm{DoA}=$ dominância absoluta, FA = frequência absoluta).

TABLE 2: Phytosociological parameters estimated for the tree species in a urban forest fragment in the municipality of Sério, RS state, Brazil, in decreasing importance value order (IVI) (NI= number of specimens, $\mathrm{AB}=$ basal area, $\mathrm{DA}=$ absolute density, DoA= absolute dominancy, $\mathrm{FA}=$ absolute frequency).

\begin{tabular}{|c|c|c|c|c|c|c|}
\hline Espécies & NI & $\begin{array}{c}\mathrm{AB} \\
\left(\mathrm{m}^{2} \cdot \mathrm{ha}^{-1}\right)\end{array}$ & $\begin{array}{c}\text { DA } \\
\left(\text { ind.ha }^{-1}\right)\end{array}$ & $\begin{array}{c}\text { DoA } \\
\left(\mathrm{m}^{2} \cdot \mathrm{ha}^{-1}\right)\end{array}$ & $\begin{array}{c}\text { FA } \\
\left(\text { ind.ha }^{-1}\right)\end{array}$ & IVI \\
\hline Alchornea triplinervia (Spreng.) Müll.Arg & 43 & 3,64 & 108 & 9,12 & 62,5 & 13,87 \\
\hline Vernonanthura discolor (Spreng.) H.Rob. & 40 & 1,69 & 100 & 4,23 & 47,5 & 8,67 \\
\hline Actinostemon concolor (Spreng.) Müll.Arg. & 56 & 0,43 & 140 & 1,09 & 37,5 & 6,42 \\
\hline Eugenia rostrifolia D.Legrand & 43 & 0,66 & 108 & 1,65 & 40 & 6,23 \\
\hline Araucaria angustifolia (Bertol.) Kuntze & 24 & 1,20 & 60 & 3,00 & 27,5 & 5,55 \\
\hline Miconia pusilliflora (DC.) Naudin & 33 & 0,24 & 82,5 & 0,61 & 40 & 4,71 \\
\hline Piptocarpha angustifolia Dusén ex Malme & 21 & 0,93 & 52,5 & 2,34 & 20 & 4,39 \\
\hline Alsophila setosa Kaulf. & 34 & 0,29 & 85 & 0,74 & 17,5 & 3,69 \\
\hline Myrsine umbellata Mart. & 17 & 0,20 & 42,5 & 0,51 & 27,5 & 2,96 \\
\hline Sorocea bonplandii (Baill.) W.C.Burger et al. & 18 & 0,20 & 45 & 0,50 & 25 & 2,88 \\
\hline Ilex paraguariensis A.St.-Hil. & 4 & 1,08 & 10 & 2,71 & 7,5 & 2,98 \\
\hline Cupania vernalis Cambess. & 18 & 0,19 & 45 & 0,49 & 17,5 & 2,47 \\
\hline Lamanonia ternata Vell. & 10 & 0,43 & 25 & 1,08 & 12,5 & 2,22 \\
\hline Cabralea canjerana (Vell.) Mart. & 5 & 0,59 & 12,5 & 1,48 & 7,5 & 1,98 \\
\hline Ocotea silvestris Vattimo-Gil & 9 & 0,32 & 22,5 & 0,81 & 12,5 & 1,92 \\
\hline Zanthoxylum rhoifolium Lam. & 11 & 0,06 & 27,5 & 0,16 & 20 & 1,88 \\
\hline Nectandra oppositifolia Nees & 17 & 0,12 & 42,5 & 0,31 & 10 & 1,86 \\
\hline Pinus elliottii Engelm. & 3 & 0,67 & 7,5 & 1,67 & 2,5 & 1,76 \\
\hline Schefflera morototoni (Aubl.) Maguire et al. & 8 & 0,17 & 20 & 0,43 & 15 & 1,66 \\
\hline Aiouea saligna Meisn. & 11 & 0,22 & 27,5 & 0,55 & 7,5 & 1,56 \\
\hline Annona neosalicifolia Raddi & 10 & 0,10 & 25 & 0,26 & 12,5 & 1,51 \\
\hline Myrsine laetevirens (Mez) Arechav. & 8 & 0,08 & 20 & 0,20 & 15 & 1,47 \\
\hline Hovenia dulcis Thunb. & 10 & 0,20 & 25 & 0,50 & 7,5 & 1,45 \\
\hline Schinus terebinthifolius Raddi & 7 & 0,14 & 17,5 & 0,37 & 12,5 & 1,42 \\
\hline Sloanea hirsuta (Schott) Planch. ex Benth. & 9 & 0,06 & 22,5 & 0,16 & 12,5 & 1,36 \\
\hline Esenbeckia grandiflora Mart. & 8 & 0,05 & 20 & 0,14 & 7,5 & 1,02 \\
\hline Endlicheria paniculata (Spreng.) J.F.Macbr. & 4 & 0,20 & 10 & 0,51 & 5 & 0,95 \\
\hline Meliosma sellowii Urb. & 1 & 0,34 & 2,5 & 0,87 & 2,5 & 0,94 \\
\hline Myrsine lorentziana (Mez) Arechav. & 4 & 0,17 & 10 & 0,43 & 5 & 0,88 \\
\hline Eugenia pyriformis Cambess. & 3 & 0,06 & 7,5 & 0,16 & 7,5 & 0,72 \\
\hline Calyptranthes tricona D.Legrand & 4 & 0,03 & 10 & 0,09 & 7,5 & 0,72 \\
\hline Casearia sylvestris $\mathrm{Sw}$. & 3 & 0,02 & 7,5 & 0,07 & 7,5 & 0,64 \\
\hline Eugenia verticillata (Vell.) Angely & 3 & 0,02 & 7,5 & 0,06 & 7,5 & 0,64 \\
\hline
\end{tabular}


TABELA 2: Continuação...

TABLE 2: Continued...

\begin{tabular}{|c|c|c|c|c|c|c|}
\hline Espécies & NI & $\begin{array}{c}\mathrm{AB} \\
\left(\mathrm{m}^{2} \cdot \mathrm{ha}^{-1}\right) \\
\end{array}$ & $\begin{array}{c}\text { DA } \\
\left(\text { ind.ha }^{-1}\right) \\
\end{array}$ & $\begin{array}{c}\text { DoA } \\
\left(\mathrm{m}^{2} \cdot \mathrm{ha}^{-1}\right) \\
\end{array}$ & $\begin{array}{c}\text { FA } \\
\left.\text { (ind.ha }{ }^{-1}\right) \\
\end{array}$ & IVI \\
\hline Stillingia oppositifolia Baill. ex Müll.Arg. & 3 & 0,04 & 7,5 & 0,12 & 5 & 0,56 \\
\hline Annona rugulosa (Schltdl.) H.Rainer & 3 & 0,02 & 7,5 & 0,07 & 5 & 0,51 \\
\hline $\begin{array}{l}\text { Allophylus edulis (A.St.-Hil. et al.) Hieron. ex } \\
\text { Niederl. }\end{array}$ & 2 & 0,05 & 5 & 0,13 & 5 & 0,50 \\
\hline Trichilia clausseni C.DC & 3 & 0,02 & 7,5 & 0,05 & 5 & 0,50 \\
\hline $\begin{array}{l}\text { Roupala montana var. brasiliensis (Klotzsch) } \\
\text { K.S.Edwards }\end{array}$ & 2 & 0.08 & 5 & 0.21 & 2.5 & 0,44 \\
\hline Matayba elaeagnoides Radlk. & 4 & 0,02 & 10 & 0,065 & 2,5 & 0,43 \\
\hline Solanum sanctae-catharinae Dunal & 2 & 0,01 & 5 & 0,033 & 5 & 0,41 \\
\hline Xylosma pseudosalzmannii Sleumer & 2 & 0,01 & 5 & 0,027 & 5 & 0,41 \\
\hline Psychotria suterella Müll.Arg. & 3 & 0,008 & 7,5 & 0,020 & 2,5 & 0,33 \\
\hline Faramea montevidensis (Cham. \& Schltdl.) & & & & & & \\
\hline DC. & 2 & 0,03 & 5 & 0,084 & 2,5 & 0,33 \\
\hline Solanum pseudoquina A.St.-Hil. & 2 & 0,01 & 5 & 0,037 & 2,5 & 0,29 \\
\hline Calyptranthes grandifolia O.Berg & 2 & 0,008 & 5 & 0,020 & 2,5 & 0,27 \\
\hline Solanum mauritianum Scop. & 1 & 0,02 & 2,5 & 0,064 & 2,5 & 0,25 \\
\hline Randia ferox (Cham. \& Schltdl.) DC. & 1 & 0,02 & 2,5 & 0,063 & 2,5 & 0,25 \\
\hline Eriobotrya japonica (Thunb.) Lindl. & 1 & 0,02 & 2,5 & 0,062 & 2,5 & 0,24 \\
\hline Gochnatia polymorpha (Less.) Cabrera & 1 & 0,02 & 2,5 & 0,060 & 2,5 & 0,24 \\
\hline Mollinedia schottiana (Spreng.) Perkins & 1 & 0,003 & 2,5 & 0,007 & 2,5 & 0,20 \\
\hline Hennecartia omphalandra J.Poiss. & 1 & 0,002 & 2,5 & 0,005 & 2,5 & 0,20 \\
\hline
\end{tabular}

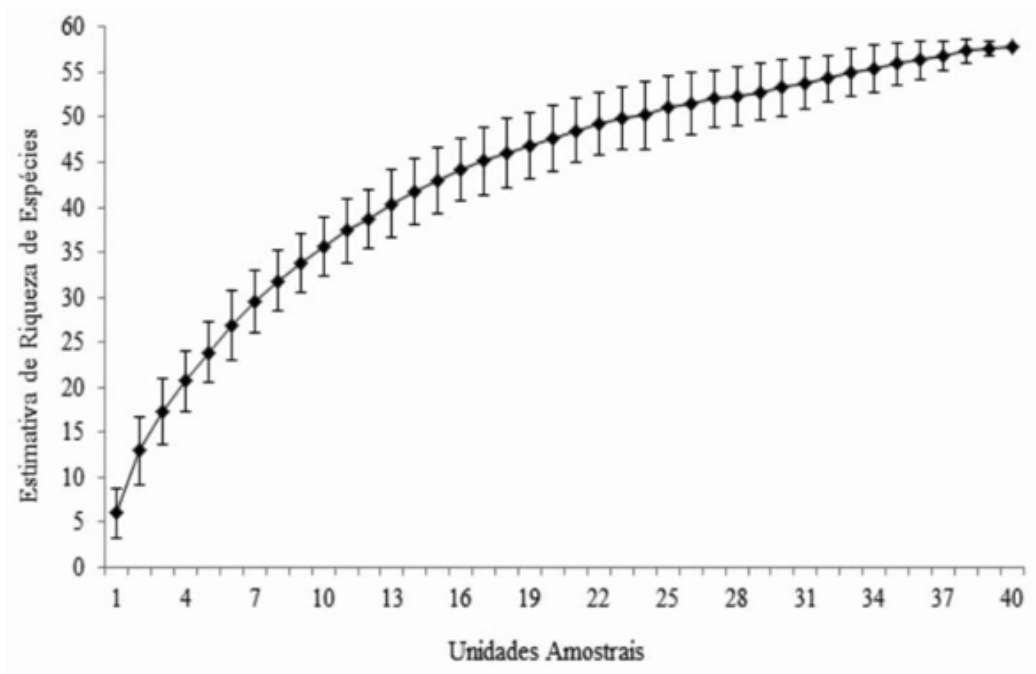

FIGURA 2: Estimativa de riqueza da comunidade arbórea de um fragmento florestal urbano no município de Sério - RS, Brasil, com base no número de espécies amostradas nas unidades amostrais, através do estimador Bootstrap. As barras correspondem ao desvio padrão.

FIGURE 2: Richness estimation of tree community in the urban forest fragments through the "Bootstrap" estimator from municipality of Sério, RS state, Brazil, based in the species number sampled from the units. Bars representing the standard deviance. 
ciológico, as famílias com maior riqueza foram as mesmas registradas no levantamento florístico: Myrtaceae e Lauraceae com 9,80 e 7,84\% do total das espécies.

A participação de espécies tropicais atlânticas ou higrófilas na composição florística local (Araucaria angustifolia e Ilex paraguariensis) confirmam a influência da Floresta Ombrófila Mista, provavelmente em razão de o fragmento estar localizado em uma região próxima a esta formação (LEITE, 2002). Ambas as espécies atingiram valores próximos de dominância no fragmento $(3,00 \mathrm{e}$ $2,71 \mathrm{~m}^{2}$. ha ${ }^{-1}$, respectivamente), indicando serem indivíduos antigos na comunidade, ressaltando que Araucaria angustifolia é a quinta espécie com o maior valor de importância no presente estudo $(5,55 \%)$.

Do total de 51 espécies, seis nativas e uma exótica (Eriobotrya japonica) foram representadas por um único indivíduo. Dessa forma, Meliosma sellowii, Solanum mauritianum, Randia ferox, Gochnatia polymorpha, Mollinedia schottiana e Hennecartia omphalandra apresentaram baixa densidade e frequência no fragmento.

O valor estimado do índice de diversidade de Shannon(H') foi de 3,35, indicando que a diversidade florística do fragmento é consideravelmente alta, pois um levantamento fitossociológico realizado em um fragmento com a mesma formação florestal da área do presente estudo, no município de Santa Maria - RS, usando um método semelhante, obteve menor valor de diversidade $\left(H^{\prime}=3,213\right)$ oriundo de maior riqueza (64 espécies) (LONGHI et al., 2000). $O$ fato de ser uma cidade criada recentemente ( $20 \mathrm{de}$ março de 1992), com uma população de apenas 2.281 habitantes (IBGE, 2010) e se tratar de um fragmento que mantém conexão com outro fragmento, podem ser fatores que estejam influenciando para que o mesmo ainda mantenha uma diversidade arbórea significativa.

A estimativa de diversidade arbórea pela equabilidade de Pielou (J) resultou em 0,85. Ao comparar com o estudo de Troian et al. (2011), que obteve um valor próximo do encontrado $(\mathrm{J}=0,88)$ em um fragmento florestal urbano no município de Porto Alegre, RS, verifica-se que ambos apresentam alta equabilidade, o que acarreta a inexistência de espécies dominantes na área.

A área no passado foi utilizada para extração de madeira formando clareiras no seu interior. É provável que esta prática tenha favorecido a presença marcante de Merostachys multiramea Hack em algumas partes do interior da mata, nas quais foi observada a ausência de indivíduos arbóreos, mostrando que se tratava de clareiras. Destaca-se também a ocorrência de Alsophila setosa, formando aglomerados em determinados locais da área, colocando-a entre as dez espécies com maior valor de importância para o fragmento (IVI=3,69\%).

\section{Padrões estruturais}

A estrutura vertical apresentou indivíduos com alturas variando de 1,5 a $20 \mathrm{~m}$, sendo que o maior valor de altura foi atribuído às espécies Vernonanthura discolor e Araucaria angustifolia, ambas com $20 \mathrm{~m}$. Os indivíduos estiveram distribuídos em todas as classes de altura estimada, com o pico mais elevado entre 4,1-5 m de altura (Figura 3), correspondendo a $18 \%$ dos indivíduos amostrados. Neste grupo destacaramse Actinostemon concolor, Eugenia rostrifolia, Miconia pusilliflora, espécies características do sub-bosque.

Avaliando os dados referentes às classes de altura (Figura 3), não foi possível distinguir mais de um estrato na floresta estudada, pois, de acordo com Teixeira et al. (1986), o presente fragmento de

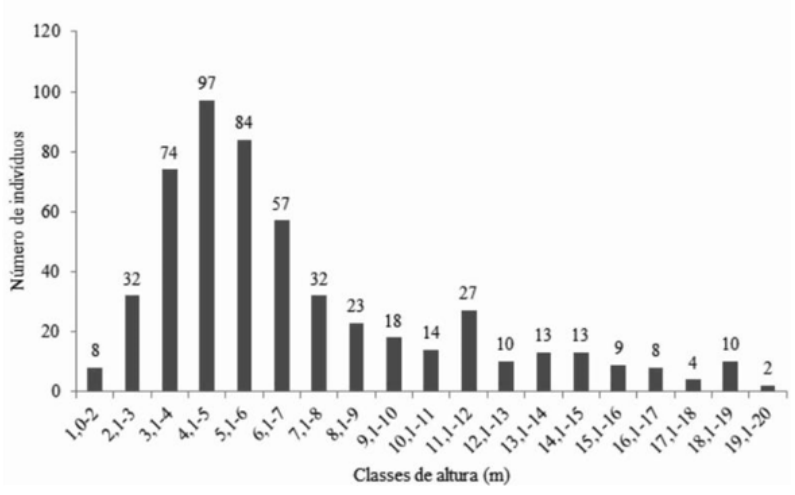

FIGURA 3: Distribuição de frequência de classes de altura dos indivíduos amostrados no fragmento florestal urbano no município de Sério - RS, Brasil.

FIGURE 3: Distribution and frequency classes of specimens height sampled in the urban forest fragment in the municipality of Sério, RS state, Brazil.

Os valores de diâmetro (DAP) variaram de 5 a $115 \mathrm{~cm}$ (Figura 4), o maior valor de circunferência encontrada pertence às espécies Alchornea triplinervia e Ilex paraguariensis. Aproximadamente metade dos indivíduos (45\%) 
estavam na menor classe de diâmetro, que corresponde 5-10 cm, Budke et al. (2004) em um estudo do componente arbóreo na floresta ribeirinha do arroio Passo das Tropas, Santa Maria - RS, utilizando-se de uma classe de diâmetro semelhante, também constataram que para metade dos indivíduos cabe a menor classe de diâmetro, sendo um indicativo de espécies pertencentes do sub-bosque e regenerantes do dossel superior.

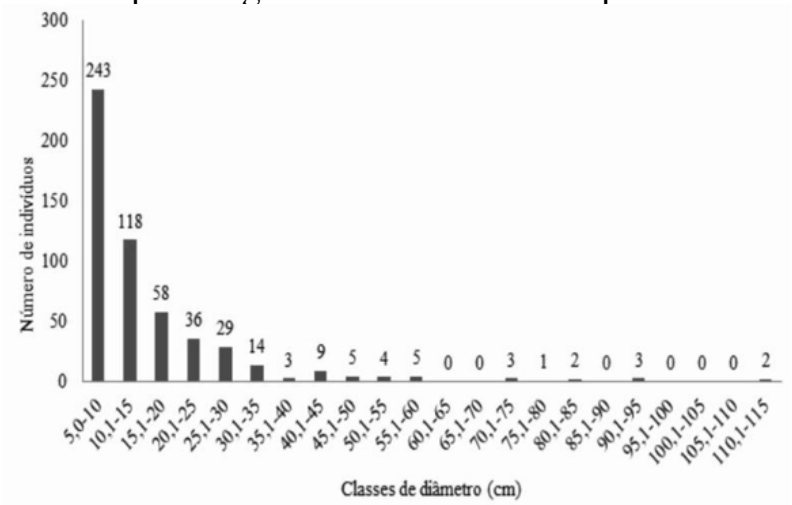

FIGURA 4: Distribuição dos indivíduos amostrados no fragmento florestal urbano no município de Sério - RS, Brasil, em intervalos de classe de diâmetro.

FIGURE 4: Sampled specimens distribution in the urban forest fragment in the municipality of Sério, RS state, Brazil. In diameter class intervals.

\section{CONCLUSÃO}

Alchornea triplinervia, Vernonanthura discolor, Actinostemon concolor e Eugenia rostrifolia foram as espécies com maior representatividade no fragmento estudado em razão do elevado número de indivíduos, frequência e área basal. Os índices de diversidade mostram que o fragmento, apesar de estar cercado por áreas antropizadas e localizado em zona urbana, apresenta bom estado de conservação.

A presença de espécies exóticas representa uma ameaça que deve ser removida com a máxima urgência. Além disso, o fragmento pode ser utilizado para projetos de Educação Ambiental, mas para isso, recomenda-se a instalação de painéis na entrada do fragmento, contendo informações sobre a área e de placas com a identificação das espécies e de orientações para a circulação no seu interior.

\section{AGRADECIMENTOS}

Ao botânico Martin Grings pelo auxílio na identificação das espécies, aos proprietários da área de estudo que permitiram a realização da pesquisa. Ao Tiago Ariotti e à Grasiela da Costa que auxiliaram nas atividades de campo.

\section{REFERÊNCIAS BIBLIOGRÁFICAS}

The Angiosperm Phylogeny Group (APG III). $\mathrm{Na}$ update of the Angiosperm Phylogeny Group classification for the orders and families of flowering plants: APG III. Botanical Journal of the Linnean Society, v. 161, n. 2, p.105-121, 2009.

BRACKMANN, C. E.; FREITAS, E. M. de. Florística arbórea e arbustiva de um fragmento de Mata Ciliar do arroio Boa Vista Teutônia, RS, Brasil. Hoehnea, São Paulo, v.40, n. 2, p. 365-372, 2013.

BRASIL. Resolução no 33. 1994. Disponível em: http:/www.mma.gov.br/port/conama/res/res94/ res3394.html Acesso em: 03/10/2013.

BUDKE, J. C. et al. Florística e fitossociologia do componente arbóreo de uma floresta ribeirinha, arroio Passo das Tropas, Santa Maria, RS, Brasil. Acta Botânica Brasílica, São Paulo, v. 3, n. 18, p. 581-589, 2004.

CIELO-FILHO, R.; SANTIN, D. A. Estudo florístico e fitossociológico de um fragmento florestal urbano -Bosque dos Alemães, Campinas, SP. Revista Brasileira de Botânica, São Paulo, v. 25, n. 3, p. 291-301, 2002.

COLWELL, R. K. EstimateS: Statistical Estimation of Species Richness and Shared Species from Samples. Version8. Connecticut: University of Connecticut, 2006. Disponível em: purl.oclc.org/ estimates. Acesso em: 30/10/2013.

CULLEN JR, L. et al. Trampolins ecológicos e zonas de benefício múltiplo: ferramentas agroflorestais para a conservação de paisagens rurais fragmentadas na Floresta Atlântica Brasileira.

Revista Natureza e Conservação, Curitiba, v. 1, n. 1, p. 37-46, 2003.

DORNELES, L. P. P.; WAECHTER, J. L. Fitossociologia do componente arbóreo na floresta turfosa do Parque Nacional da Lagoa do Peixe, Rio Grande do Sul. Acta Botânica Brasílica, São Paulo, v. 4, n. 18, p. 815-824, 2004.

FILGUEIRAS, T. S. et al. Caminhamento - um método expedito para levantamentos florísticos qualitativos. Cadernos de Geociências, Rio de Janeiro, n. 12, p. 39-43, 1994.

FEIBER, S. D. Áreas verdes urbanas imagem e uso-O caso do Passeio Público de Curitiba - PR. 
Revista RA'E GA- O Espaço Geográfico em Análise, Curitiba, n. 8, p. 93-105, 2004.

GUREVITCH, J.; SCHEINER, S. M.; FOX, G. A. Ecologia vegetal. Porto Alegre: Artmed, 2009.592 p.

GRINGS, M.; BRACK, P. Árvores na vegetação nativa de Nova Petrópolis, Rio Grande do Sul. Iheringia, Série Botânica, Porto Alegre, v. 64, n. 1, p. 5-22, 2009.

HACK, C. et al. Análise fitossociológica de um fragmento de floresta estacional decidual no município de Jaguari, RS.Ciência Rural, Santa Maria, v. 35, n.5, p. 1083-1091, 2005.

INSTITUTO BRASILEIRO DE GEOGRAFIA E ESTATÍSTICA (IBGE). Censo Demográfico. Diário Oficial da União. 04.11.2010. Disponível em: http://www.ibge.gov.br/home/estatistica/ populacao/censo2010/ resultados_dou/RS2010.pdf Acesso em: 31/10/2013.

JARENKOW, J.A.; WAECHTER, J. L. Composição, estrutura e relações florísticas do componente arbóreo de uma floresta estacional no Rio Grande do Sul, Brasil. Revista Brasileira de Botânica, São Paulo, v. 24, n. 3, p. 263-272, 2001.

JURINITZ, C. F.; JARENKOW, J. A. Estrutura do componente arbóreo de uma floresta estacional na Serra do Sudeste, Rio Grande do Sul, Brasil. Revista Brasileira de Botânica, São Paulo, v. 26, n. 4, p.475-487, 2003.

LEITE, P. F. Contribuição ao conhecimento fitoecológico do Sul do Brasil. Ciência \& Ambiente, Santa Maria, v.1, n.24, p. 51-73, 2002.

Lista de Espécies da Flora do Brasil. 2013. Disponível em: http://floradobrasil.jbrj. gov.br. Acesso em: 20/07/2013.

LONGHI, S. J. et al. Aspectos fitossociológicos de fragmento de Floresta Estacional Decidual, Santa Maria, RS. Ciência Florestal, Santa Maria, v.10, n.2, p. $59-74,2000$.

MARKUS, E.; FREITAS, E. M.de. Florística arbórea de uma porção de mata de encosta do Morro da Harmonia, Teutônia, Rio Grande do Sul, Brasil. Pesquisas, Botânica, São Leopoldo, n.62, p. 2632722011.

MELO, A. G. C. de. et al.Fragmentos Florestais Urbanos. Revista Científica Eletrônica de Engenharia Florestal R. C. E. E. F., São Paulo, v. 17, n.1, p. 58-79, 2011.

MUELLER-DOMBOIS, D.; ELLENBERG, H. Aims and methods of vegetation ecology. J. Wiley, New York, 547 p. 1974.

PEEL, M. C.; FINLAYSON, B. L.; MCMAHON, T. A. Updated world map of the Koppen-Geiger climate classification. Hydrology and Earth System, Sciences, v. 11, p. 1633-1644, 2007.

SOBRAL, M. et al. (Org.).Flora arbórea e arborescente do Rio Grande do Sul, Brasil. 2. ed. São Paulo: RIMA Editora, 2013,p. 357.

SEMA, 2003. Lista final das espécies da flora ameaçadas - RS. Disponível em: $<$ (http://www.fzb. rs.gov.br/downloads/flora_ameacada.pdf) $>$. Acesso em: 27/10/ 2013.

STRECK, E. V. et al. Solos do Rio Grande do Sul. 2. ed. Porto Alegre: Emater/RS-Ascar, 2008, p.222. TEIXEIRA, M. B. et al. Vegetação. In: IBGE, Levantamento de Recursos Naturais, v. 33. Rio de Janeiro, IBGE, 1986. p. 541-620.

TROIAN, L. C. et al. Florística e padrões estruturais de um fragmento florestal urbano, região metropolitana de Porto Alegre, RS, Brasil. Iheringia, Série Botânica, Porto Alegre, v. 66, n. 1, p. 5-16,2011.

Tropicos.org. Missouri Botanical Garden.

Disponível em: $<$ (http://www.tropicos.org) $>$.Acesso em: 27/07/ 2013. 